8 Research Square
Preprints are preliminary reports that have not undergone peer review.

They should not be considered conclusive, used to inform clinical practice, or referenced by the media as validated information.

\title{
Clinical Outcomes Observation in Stage IIB-III Cervical Cancer Treated by Adjuvant Surgery Following Concurrent Chemoradiotherapy
}

\section{Yong Li}

the affiliated hospital of qingdao university

\section{Zhiying Chen}

the Affiliated Hospital of Qingdao University

\section{Xiang Wang}

the Affiliated Hospital of Qingdao University

Xiumei Li

the Affiliated Hospital of Qingdao University

Jie Zhou

the Affiliated Hospital of Qingdao University

Yongchun Zhang ( $\nabla$ summermed@126.com )

the Affiliated Hospital of Qingdao University

\section{Research}

Keywords: Cervical cancer, concurrent chemoradiation, surgery, recurrence

Posted Date: August 12th, 2020

DOl: https://doi.org/10.21203/rs.3.rs-53507/v1

License: () (1) This work is licensed under a Creative Commons Attribution 4.0 International License. Read Full License 


\section{Abstract}

Objective: To explore the feasibility of adjuvant surgery following concurrent chemoradiation therapy $(C C R T)$ in stage $\triangle \mathrm{B}-\mathbb{Q}$ cervical cancer. And analyze risk factors of recurrence after surgery.

Methods: Forty-nine patients diagnosed with stage $\varangle \mathrm{B}-\llbracket$ cervical cancer were reviewed retrospectively. Investigated the risk factors of recurrence after surgery using Chi-squared Test and further analyzed multiple factors affecting postoperative recurrence using the multi-factor logistic regression. Furthermore, the correlation of surgery outcomes (including operation time, bleeding, and hospitalization date and surgery complications) with the time which carried out between CCRT and completion surgery was analyzed.

Results: Tumor histology and residual tumor in the cervix were significantly associated with postoperative recurrence $(P=0.014$ and $P=0.040$, respectively). Logistic regression analysis demonstrated that the independent risk factors of postoperative recurrence were age and residual tumor in the cervix $(P=0.017$ and $P=0.030$, respectively). Compared with completion surgery was carried out $\leq 6$ weeks after CCRT, the operation time, bleeding, hospitalization date and surgery complications were more than $>6$ weeks group. Moreover, bleeding and surgery complications were statistically significant $(P=0.019$ and $P=$ 0.044 , respectively).

Conclusion: CCRT combined surgery for stage $\triangle \mathrm{B}-\otimes$ cervical cancer was feasible, reduced the rate of postoperative recurrence and surgery complications were tolerated. CCRT combined surgery might improve the local control of lesion.

\section{Introduction}

Cervical cancer is a worldwide major public health issue. It is the second most common malignancy in women and represents the third-leading cancer in women worldwide [1]. Approximately 500,000 new cases and 237,500 deaths of cervical cancer occur annually. Advanced cervical cancer is not easy to control and has poor prognosis because of the lymph node metastasis or distant metastasis. Cisplatinbased concurrent chemoradiotherapy is the standard treatment for advanced cervical cancer, but the local recurrence rate after chemoradiotherapy is high and 5-year survival rate is only 50 to 65 percent [2]. In order to further improve the local control rate of cervical cancer and improve the 5-year survival rate, many scholars have explored the efficacy and safety of concurrent radiotherapy and chemotherapy combined with surgery in the treatment of advanced cervical cancer [3]. Some studies have reported that CCRT combined surgery can improve local lesion control and overall survival, but the role of adjuvant surgery is still controversial, because these studies differ in disease stage, surgical scope, and form of CCRT (radiotherapy dose, internal irradiation or not, and type of chemotherapy) [4]. The purpose of this

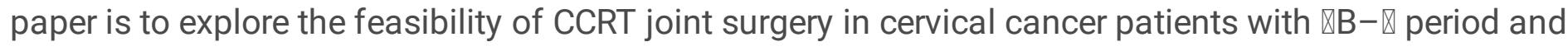
retrospectively analyze the related factors of postoperative recurrence. 


\section{Materials And Methods}

\section{Patients}

This study includes 49 patients with biopsy proven cervical cancer between June 2006 and October 2012 was treated in department of Radiotherapy Center and Gynecology of the Affiliated Hospital of Qingdao University. The Institutional Review Board approved this study and informed consent was obtained. Inclusion criteria: a) Eastern Cooperative Oncology Group (ECOG) status was less than or equal to $1 ; b$ ) International Federation of Gynecology and Obstetrics (FIGO) stages $₫ \mathrm{~B}-\bigotimes$ cervical cancer through gynecological examination by two veteran gynecologic oncologists; $\mathrm{C}$ ) All patients underwent a medical history, gynecological examination; punch biopsy, chest X-ray, pelvic magnetic resonance imaging (MRI) and transvaginal ultrasound (TVS). Exclusion criteria: a) Patients with serious heart, lung, liver or hematologic system disease; b) Patients with other cancer; c) Treatment was interrupted or radiotherapy did not reach the radical dose; d) Lost to follow-up or death from other causes.

\section{CCRT}

All patients completed the radical radiotherapy in department of Radiotherapy Center. Patients were immobilized with a body net in the supine position and underwent a computed tomography (CT) simulation scan (General Electric, Milwaukee WI, USA) with intravenous contrast, using $5 \mathrm{~mm}$ slice thickness. Simulation images extended from $L 1$ to $5 \mathrm{~cm}$ below the ischial tuberosities. The gross tumor volume (GTV), clinical target volume (CTV) and planning target volume (PTV) were defined according to Radiation Therapy Oncology Group (RTOG) guidelines. The CTV-high risk included the GTV, parametrium, the upper part of the vagina to $3 \mathrm{~cm}$ below the tumor invasion, and metastasis lymph node. The CTV-low risk included the CTV-high risk and regional lymph nodes (common, external, internal iliac lymph nodes, obturator and presacral lymph nodes). The treatment planning was designed and computed using the Plato system version 2.7.5 (Varian, USA). The external radiation dose was 40-50 Gy in 20-25 fractions with 2 Gy per fraction using a linear accelerator (Trilogy, Varian, USA). And followed by high-dose-rate brachytherapy to $90 \%$ of the high-risk CTV was delivered with 30-40 Gy using an intracavity applicator (microSelectron-HDR Ir-192 set; Nucletron, Veenendaal, Netherlands). All patients received concomitant chemotherapy of cis-platinum $\left(40 \mathrm{mg} / \mathrm{m}^{2}\right)$ alone every week starting with external radiotherapy (4-5 circles).

\section{Adjacent surgery}

After reevaluated the relationship between cervix, bladder, rectum and parauterine tissue through gynecological examination and pelvic MRI, all patients underwent extrafascial hysterectomy with adnexectomy followed by CCRT. According to postoperative pathology, nine patients with invading $1 / 2$ of the cervical stroma recived 4 circles chemotherapy consisted of the association of cis-platinum $(100 \mathrm{mg} /$ $\left.\mathrm{m}^{2}\right)$ in combination with paclitaxel $\left(135 \mathrm{mg} / \mathrm{m}^{2}\right)$.

\section{Follow-up}


Patient follow-up was designed to be conducted every 3 months during the first two years and every 6 months over the next three years after surgery. The follow-up included gynecological examination, TVS, vaginal apical cytology, abdominal plevic and chest CT.

\section{Statistical analysis}

All data were performed using SPSS 20.0 (Chicago IL, USA). Quantitative data are expressed as the mean \pm standard deviation (S.D.). $\square^{2}$ test or Fisher exact test was used to evaluate categorical variable. Groups were compared using Student's $t$-test. . Multivariate analysis of prognostic factors was performed with Cox proportional hazards regression. A $p<0.05$ was regarded as statistically significant.

\section{Results}

After the combination of CCRT and surgery, recurrence of disease was observed in 12 (22.4\%) patients, which were distributed as follows: 9 local recurrences and 3 distant metastases ( 1 lung metastasis and 2 bone metastases). Median follow-up from the date of surgery was 76 months (range 29129 months), and 5 patients died during follow-up. The 3-year OS and 5-year OS were $95.9 \%$ and $89.8 \%$, respectively.

The correlations of major clinical/pathological factors and recurrence after CCRT and adjacent surgery in LACC were summarized in Table 1. Median age of 49 patients was 49 years (range 29-66) and there was statistically significant difference between age and recurrence of disease $(P=0.023)$. 
Table 1

Correlations of major clinical/pathological factors and recurrence after CCRT and adjacent surgery in stage $\triangle \mathrm{B}-\llbracket$ cervical cancer

\begin{tabular}{|c|c|c|c|c|c|c|}
\hline \multirow[t]{2}{*}{ Factors } & & \multirow{2}{*}{$\begin{array}{l}\text { Number } \\
(\%)\end{array}$} & \multicolumn{2}{|c|}{ Recurrence } & \multirow[t]{2}{*}{$x^{2}$} & \multirow[t]{2}{*}{$p$} \\
\hline & & & No & Yes & & \\
\hline Age & $\varangle 50$ & $28(57.1)$ & 50 & 3 & 5.168 & $0.023 *$ \\
\hline HPV infection & $\geq 50$ & $21(42.9)$ & 13 & 8 & 0.464 & 0.496 \\
\hline Tumor diameters & No & $31(63.3)$ & 25 & 6 & 1.107 & 0.293 \\
\hline \multirow{2}{*}{$\begin{array}{l}\text { Pathological } \\
\text { differentiation }\end{array}$} & Yes & 18(36.7) & 13 & 5 & 0.979 & 0.613 \\
\hline & $\leq 4 \mathrm{~cm}$ & $20(40.8)$ & 14 & 6 & 1.954 & 0.162 \\
\hline $\begin{array}{l}\text { Pathologic } \\
\text { subtypes }\end{array}$ & $\otimes 4 \mathrm{~cm}$ & $29(59.2)$ & 24 & 5 & 0.657 & 0.720 \\
\hline FIGO stage & High & $7(14.3)$ & 5 & 2 & 8.920 & $0.012^{*}$ \\
\hline \multirow{10}{*}{$\begin{array}{l}\text { Microscopic } \\
\text { residual }\end{array}$} & Moderatly & $33(67.3)$ & 25 & 8 & & \\
\hline & Low & $9(18.4)$ & 8 & 1 & & \\
\hline & Adenocarcinoma/mixed subtypes & $7(14.3)$ & 4 & 3 & & \\
\hline & SCC & $42(85.7)$ & 34 & 8 & & \\
\hline & IIB & $41(83.7)$ & 32 & 9 & & \\
\hline & IIIA & $1(2.0)$ & 1 & 0 & & \\
\hline & IIIB & $7(14.3)$ & 5 & 2 & & \\
\hline & No & $27(55.1)$ & 20 & 7 & & \\
\hline & Disease invading less than $50 \%$ of & $13(26.5)$ & 13 & 0 & & \\
\hline & $\begin{array}{l}\text { Disease invading more than } 50 \% \\
\text { of the myometrium }\end{array}$ & $9(18.4)$ & 5 & 4 & & \\
\hline
\end{tabular}

After adjacent surgery, 27 patients (55.1\%) showed a complete response to CCRT treatment, and 22 cases (44.9\%) showed a microscopic residual disease (9 cases with disease invading more than $50 \%$ of the myometrium and 13 cases with disease invading less than $50 \%$ of the myometrium). There was statistically significant difference between recurrence of disease and microscopic residual $(P=0.012)$. On multivariate analysis showed both age and microscopic residual were highly correlated with recurrence of disease (Table 2) $(P=0.017$ and $P=0.030$, respectively).Although there was not statistically significant difference between tumor diameters and recurrence of disease, tumor diameters was highly correlated with microscopic residual on further analysis (Table 3). 
Table 2

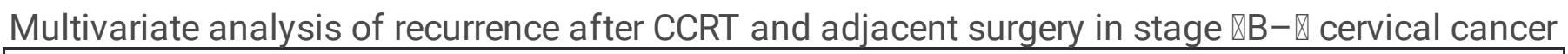

\begin{tabular}{|llllll|}
\hline Parameters & $\boldsymbol{\beta} \boldsymbol{i}$ & $\mathbf{S . E}$ & Walds & $\boldsymbol{P}$ & $\operatorname{Exp}(\boldsymbol{B}) \mathbf{9 5 \%} \mathbf{C l}$ \\
\hline Age & 3.222 & 1.351 & 5.691 & $0.017 *$ & $25.086(1.777 \sim 354.179)$ \\
HPV infection & 1.290 & 1.173 & 1.211 & 0.271 & $3.633(0.365 \sim 36.167)$ \\
Tumor diameters & -0.336 & 1.125 & 0.089 & 0.765 & $0.715(0.079 \sim 6.476)$ \\
Pathological differentiation & 1.153 & 1.659 & 0.483 & 0.487 & $3.168(0.123 \sim 81.769)$ \\
Pathologic subtype & -1.586 & 1.660 & 0.913 & 0.339 & $0.205(0.008 \sim 5.296)$ \\
FIGO stage & -2.521 & 2.201 & 1.312 & 0.252 & $0.080(0.001 \sim 6.008)$ \\
Residual cancer & -3.274 & 1.506 & 4.723 & $0.030 *$ & $0.038(0.002 \sim 0.725)$ \\
Constant & 1.176 & 2.907 & 0.369 & 0.544 & \\
\hline CCRT, concurrent chemoradiotherapy; ${ }^{*}$ P $₫ 0.05$ & & & \\
\hline
\end{tabular}

Table 3

The relationship between macroscopic residual and clinical/pathological factors

\begin{tabular}{|c|c|c|c|c|c|}
\hline \multirow[t]{2}{*}{$\begin{array}{l}\text { clinical/pathological } \\
\text { factors }\end{array}$} & & \multicolumn{2}{|c|}{$\begin{array}{l}\text { Macroscopic } \\
\text { residual }\end{array}$} & \multirow[t]{2}{*}{$x^{2}$} & \multirow[t]{2}{*}{$p$} \\
\hline & & No & Yes & & \\
\hline Tumor diameters & $\leq 4 \mathrm{~cm}$ & 18 & 2 & 14.337 & $\varangle 0.001^{\star}$ \\
\hline \multirow{6}{*}{$\begin{array}{l}\text { Pathological } \\
\text { differentiation } \\
\text { Pathologic subtype }\end{array}$} & $\nabla 4 \mathrm{~cm}$ & 9 & 20 & 0.017 & 0.992 \\
\hline & High & 4 & 3 & 0.086 & 0.769 \\
\hline & Moderately & 18 & 5 & & \\
\hline & Low & 5 & 4 & & \\
\hline & $\begin{array}{l}\text { Adenocarcinoma/mixed } \\
\text { subtypes }\end{array}$ & 3 & 4 & & \\
\hline & ScC & 24 & 18 & & \\
\hline
\end{tabular}

In early postoperative period ( $\leq 30$ days), 2 incomplete intestinal obstruction and 3 deep venous thrombosis were found. As far as long-term postoperative period (> 30 days), 3 complications were observed: 2 patients developed colorectal fistula and 1 patient showed pelvic pain.

The average of operation time was $2.0 \pm 0.4 \mathrm{~h}$ (range 1.2-3.1 h) and blood loss during the surgery was $133.5 \pm 66.7 \mathrm{~mL}$ (range $50-400 \mathrm{~mL}$ ). The average hospital stay was $9.4 \pm 2.1$ days (range $6-15$ days). The relationship between the time to start operation after CCRT and blood loss during the surgery, 
hospital stay and postoperative complication were analyzed furthermore (Table 4). Although blood loss during the surgery, hospital stay and postoperative complication in $>6$ weeks group were less than that in $\leq 6$ weeks group, only blood loss during surgery and postoperative complication were closely related with the time to start operation after CCRT $(F=5.866, P=0.019 ; F=4.056 \square P=0.044)$.

Table 4

The evaluation of operation time

\begin{tabular}{|c|c|c|c|c|c|c|c|c|c|}
\hline \multirow[t]{2}{*}{ Groups } & \multirow{2}{*}{$\begin{array}{l}\text { Operation } \\
\text { time } \\
\text { (h) }\end{array}$} & \multirow[t]{2}{*}{$p$} & \multirow{2}{*}{$\begin{array}{l}\text { Bleeding } \\
(\mathrm{mL})\end{array}$} & \multirow[t]{2}{*}{$p$} & \multirow{2}{*}{$\begin{array}{l}\text { Hospital } \\
\text { stay } \\
\text { (day) }\end{array}$} & \multirow[t]{2}{*}{$p$} & \multicolumn{2}{|c|}{ Complications } & \multirow[t]{2}{*}{$p$} \\
\hline & & & & & & & No & Yes & \\
\hline $\begin{array}{l}\leq 6 \\
\text { weeks }\end{array}$ & $\begin{array}{l}1.812 \pm \\
0.376\end{array}$ & 0.942 & $\begin{array}{l}147.41 \pm \\
78.377\end{array}$ & $0.019 *$ & $\begin{array}{l}9.740 \pm \\
2.141\end{array}$ & 0.225 & 20 & 7 & $0.044^{*}$ \\
\hline 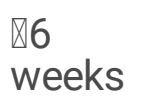 & $\begin{array}{l}1.944 \pm \\
0.368\end{array}$ & & $\begin{array}{l}115.70 \pm \\
43.425\end{array}$ & & $\begin{array}{l}9.050 \pm \\
2.081\end{array}$ & & 21 & 1 & \\
\hline
\end{tabular}

\section{Disscussion}

Local and distant recurrence is the main reason for the failure of treatment of locally advanced cervical cancer. Studies have reported that CCRT can improve the local control of lesions, progression-free survival and total survival in patients with locally advanced cervical cancer. Some researchers $[5,6]$ believe that the control of local lesions can improve the surgical resection rate. At present, there are few studies on adjuvant surgery, which is controversial for further reducing recurrence rate and improving prognosis. In this study, a total of 49 patients with locally advanced cervical cancer were included. The lesions all shrank to different degrees after CCRT treatment, among which 18 patients showed significant improvement in paratactic infiltration. About 3-9 weeks after CCRT treatment, all patients underwent extrafascial hysterectomy and bilateral adnexectomy, and the incidence of postoperative complications was $16.3 \%$, similar to $19.8 \%$ in the previous study [7]. 9 cases of patients were proved to be local recurrence with pathologically, and distant metastasis was observed in 3 patients. The recurrence rate (22.4\%) was little higher compared with the previous work, which $192 \square \mathrm{B}-\triangle \mathrm{A}$ stage cervical cancer patients was included. The recurrence rate in our study is slightly higher than CCRT joint surgery (16.7\%), however, there was a decrease compared to CCRT alone (31.7\%). Maybe it was the small sample size that led to such different results.

This study showed that pathological cancer residue was closely related to recurrence, and multivariate analysis of variance showed that cancer residue was an independent risk factor for postoperative recurrence, which was consistent with previous research results $[7,8]$. Further study found that residual carcinoma associated with preoperative lesions in diameter, suggesting that patients with tumor lesions of large diameter were more likely to relapse. The higher recurrence rate may be associated with the lack of oxygen in the center of tumors, which leading to a decrease in the sensitivity of tumor cells to radiation 
and weakens the efficacy of radiotherapy [9]. In this study, postoperative pathological types were significantly correlated with postoperative recurrence. The recurrence rate of patients with simple squamous cell carcinoma was lower than other pathological types. This may because squamous cell carcinoma has higher radiosensitivity than other pathological types [10]. In this study, multivariate analysis of variance showed that age was also an independent risk factor for postoperative recurrence, which may be related to difference in hormone and immune levels in different age groups. However, it is still controversial whether age is related to recurrence and prognosis. Other previous studies [11] have pointed out that the degree of tumor differentiation can affect the sensitivity of tumor cells to radiation. However, this study did not suggest that the degree of differentiation of cervical cancer is related to local recurrence. This may be related to the small number of included cases and the uneven proportion of the degree of differentiation and a large sample study is needed for further validation. In this study, the incidence of postoperative complications was $16.3 \%$, mainly due to mild myelosuppression and gastrointestinal reactions. The 2 cases of postoperative incomplete intestinal obstruction and intestinal fistula recovered after conservative treatment. By contrast to the previous studies (12.8-19.8\%), the complication rate was within an acceptable range in our study $[12,13]$. In addition, in this study, the time between the CCRT and surgery was compared in different group. By comparing the operative time, bleeding volume and postoperative complications, the interval > 6weeks group was better than the group with interval $\leq 6$ weeks and the result was statistically different. By analyzing the reason, the tissue was still in a state of hyperemia and edema after chemoradiotherapy, so the risk of bleeding and infection after operation in short-interval increased. Therefore, appropriately extending the time between CCRT and surgery can reduce intraoperative bleeding and facilitate postoperative recovery.

This study retrospectively analyzed the cervical cancer patients with $₫ \mathrm{~B}-\otimes$ stage who accepted extrafascial hysterectomy and bilateral adnexectomy hysterectomy surgery after CCRT. The postoperative recurrence rate decreased than pure CCRT treatment and there was no obvious increase in postoperative complications. The joint is expected to improve the local control rate of locally advanced cervical cancer patients and improve the long-term curative effect.

\section{Declarations}

\section{Acknowledgements}

Not applicable.

\section{Authors' contributions}

Yongchun Zhang, conception; Yong Li and Yongchun Zhang, design of the work; Xiumei Li and Jie Zhou, the acquisition, analysis; Yong Li, drafted the work; Zhiying Chen and Xiang Wang, interpretation of data.

\section{Competing interests}

The authors declare that they have no competing interests. 


\section{Funding}

Not applicable.

\section{Availability of data and materials}

All data generated or analyzed during this study are included in this published article.

\section{Ethics approval and consent to participate}

This study was approved by the Affiliated Hospital of Qingdao University (the Institutional Review Board).

\section{Consent for publication}

Not applicable.

\section{References}

1. Wei LC, Wang N, Shi M, Liu JY, Li JP, Zhang Y, Huang YH, Li X, Chen Y: Clinical outcome observation of preoperative concurrent chemoradiotherapy/radiotherapy alone in 174 Chinese patients with local advanced cervical carcinoma. Onco Targets Ther 2013, 6:67-74.

2. Chereau E, C DLH, Ballester M, Monnier L, Rouzier R, Touboul E, Darai E: The role of completion surgery after concurrent radiochemotherapy in locally advanced stages IB2-IIB cervical cancer. Anticancer Res 2013, 33:1661-1666.

3. Houvenaeghel G, Lelievre L, Gonzague-Casabianca L, Buttarelli M, Moutardier V, Goncalves A, Resbeut M: Long-term survival after concomitant chemoradiotherapy prior to surgery in advanced cervical carcinoma. Gynecol Oncol 2006, 100:338-343.

4. Malzoni M, Spina V, Perniola G, Aleandri V, Mossa B, luele T, Imperato F: Laparoscopic surgery in treatment of stage Ilb cervical cancer after neoadjuvant chemotherapy. A case report and review of the literature. Eur J Gynaecol Oncol 2003, 24:393-397.

5. Ota T, Takeshima N, Tabata T, Hasumi K, Takizawa K: Adjuvant hysterectomy for treatment of residual disease in patients with cervical cancer treated with radiation therapy. $\mathrm{Br} \mathrm{J}$ Cancer 2008, 99:1216-1220.

6. Classe JM, Rauch P, Rodier JF, Morice P, Stoeckle E, Lasry S, Houvenaeghel G, Groupe des Chirurgiens de Centre de Lutte Contre le C: Surgery after concurrent chemoradiotherapy and brachytherapy for the treatment of advanced cervical cancer: morbidity and outcome: results of a multicenter study of the GCCLCC (Groupe des Chirurgiens de Centre de Lutte Contre le Cancer). Gynecol Oncol 2006, 102:523-529.

7. Sun L, Sheng X, Jiang J, Li X, Liu N, Liu Y, Zhang T, Li D, Zhang X, Wei P: Surgical morbidity and oncologic results after concurrent chemoradiation therapy for advanced cervical cancer. Int $\mathrm{J}$ Gynaecol Obstet 2014, 125:111-115. 
8. Hirakawa M, Nagai Y, Toita T, Kudaka W, Inamine M, Ogawa K, Murayama S, Aoki Y: High-risk group for locoregional recurrence in patients with stage IB-IIB squamous cell carcinoma of the cervix treated with concurrent chemoradiotherapy. Anticancer Res 2011, 31:1437-1441.

9. Gray LH, Conger AD, Ebert M, Hornsey S, Scott OC: The concentration of oxygen dissolved in tissues at the time of irradiation as a factor in radiotherapy. $\mathrm{Br} \mathrm{J}$ Radiol 1953, 26:638-648.

10. Ferrandina G, Margariti PA, Smaniotto D, Petrillo M, Salerno MG, Fagotti A, Macchia G, Morganti AG, Cellini N, Scambia G: Long-term analysis of clinical outcome and complications in locally advanced cervical cancer patients administered concomitant chemoradiation followed by radical surgery. Gynecol Oncol 2010, 119:404-410.

11. Kim YH, Chung WK, Jeong JU, Cho IJ, Yoon MS, Song JY, Nam TK, Ahn SJ, Lee DH, Yoon TM, et al: Evaluation of Prognostic Factors for the Parotid Cancer Treated With Surgery and Postoperative Radiotherapy. Clin Exp Otorhinolaryngol 2019.

12. Mariagrazia D, Anna F, Gabriella F, Francesco F, Daniela S, Giuseppe D, Alessio M, Giovanni S: Preoperative chemoradiotherapy in locally advanced cervical cancer: long-term outcome and complications. Gynecol Oncol 2005, 99:S166-170.

13. Trimbos JB, Franchi M, Zanaboni F, Velden J, Vergote I: 'State of the art' of radical hysterectomy; current practice in European oncology centres. Eur J Cancer 2004, 40:375-378. 